AFRICAN

\title{
Prospects for Korean Studies in Africa: The case of The University of Nairobi*
}

\author{
By Peter Wasamba**
}

Faculty of Arts, University of Nairobi

Nairobi, Kenya

\begin{abstract}
This paper discusses trends and prospects of Korean Studies in Kenya and Africa in general. The presentation is divided into five parts, namely: An introduction; The Korean Studies Project; the trends of the Korean Studies in Kenya; the results in Kenya; and the suggestions on how to develop and promote Korean studies in Kenya and African continent. I advance an argument that prospects for promoting Korean studies are bright based on internationalisation programmes pursued by many universities in Africa. Another enabling factor is the foreign policy shift in African countries to an enhanced engagement with East Asian countries mainly China, Japan and Korea as opposed to Europe and North America. In conclusion, I argue that a lot still needs to be done in terms of capacity strengthening, infrastructural support and having a focal point for supporting Korean Studies in Africa.
\end{abstract}

*This work was supported by the Academy of Korean Studies Grant funded by the Korean Government (MEST)(AKS-2010-ANS-2012).

**Peter Wasamba is an Associate Professor and the Associate Dean at the Faculty of Arts at the University of Nairobi, Kenya. He is also the officer in charge of international collaboration in the College of Humanities and Social Sciences. 


\section{Introduction}

Asian studies has in the past not attracted much interest from students and staff at the University of Nairobi. For decades, studies on Asian societies and cultures have remained scarce in Africa, because of the Eurocentric and American frameworks that have dominated African academic circles since the colonial era. This situation has, however, existed because language and communication barriers make it difficult for researchers and scholars from Africa and East Asia to share their views. The situation has changed rapidly in the past decade with Chinese, Korean, Japanese and Indian Studies being included in the university curriculum. Korean Studies projects have been implemented at the University of Nairobi, Kenya since November 2010. Out of the four areas mentioned, it is the Chinese Studies that commands the lead in terms of the number of students enrolled in the programme, local and international staff servicing the institutive and the volume of exchange students, both inward and outward-bound. The second most popular Asian Studies programme at the university is Korean Studies which was officially launched in 2013. It is in this regard that this paper explores prospects for Korean studies in Africa with the University of Nairobi as a case study.

\section{The idea of Korean Studies in Africa}

The partnership between the University of Nairobi and the Academy of Korean Studies (AKS) was mooted at an international workshop on Korean Studies hosted by AKS on 26th November 2009. The workshop was attended by two scholars from the University of Nairobi: Dr. Wilfred Nyangena, an Economics researcher and this author, a literary scholar. One of the topics for discussion was "How to introduce Korean Studies in Africa." I presented a paper entitled, "Collaboration between Kenyan and Korean Oral Literature Scholars: What the Academy of Korean Studies (AKS) needs to know" (Wasamba, 2010). Dr. Nyangena presented a paper on "South Korean Economic Growth Model and its implications for Kenya"(Nyangena, 2010). In our presentations, we introduced the University of Nairobi and its strategic interests in East Asian Studies. We justified the introduction of Korean Studies in Africa with Kenya as a launching pad and outlined the steps 
AFRICAN

EAST-ASIAN

AFFAIRS

needed to achieve the goal. The immediate outcomes of the conference were: the admission of two University of Nairobi students to the Graduate School at the AKS; and the funding of two Korean Studies Incubation projects at the University of Nairobi through the then Strategic Initiative for Korean Studies (SIKS), currently known as the Korean Studies Promotion Service (KSPS). The projects were; "Voices from the Cities: A Comparative Study on Urbanization in Kenya and Korea," which ran from 1 November 2010 to 31 October 2012, and "Bridging the Divide: Korean Studies Networking Project," from 1 November 2010 to 31 October 2013. The latest project to be funded by AKS is The Establishment of Korean Studies at the University of Nairobi (2012-2015). It is therefore appropriate that after nearly five years from the first workshop on the prospects of Korean studies in Africa, and four years since AKS started funding projects at the University of Nairobi, we reflect on the trends of Korean Studies in Kenya and Africa and future prospects.

\section{The University of Nairobi}

It is essential to look at Asian studies in Africa within the larger context of university education in the continent, strategies for internationalisation and prospects for Asian studies. Is embracing Asian studies a product of internalisation efforts by African universities? Or is it a product of geo-political realignment by African countries to tap emerging opportunities in the East? The scope of this paper does not allow us to address these strategic questions. Instead, we look at how embracing internationalisation by the University of Nairobi has facilitated growth in Asian Studies locally. Internationalisation is generally described as the process of increased international cooperation and mobility of both students and faculty and the enhanced international orientation of curricula and programme structures (Mohamedbhai 2003:153). Internationalisation cannot be analyzed independently from the process of globalisation, which constitutes the fundamental context in which the internationalisation of higher education has been taking place (Langthaler, 2010:19). In education, globalisation mainly refers to the emergence of different forms of trans-border educational provision and of a global education market, which tends to blur national systems of education (Varghese 2009:14). In practice, the 
globalisation of education has taken the form of commoditization. Whereas globalisation is an extension of historical imbalances linked to Western colonisation and dominance, internationalisation has the potential to create more equitable relations (Young 2002: 81).

Africa's international academic relations or exchanges flow in two directions: among the African countries themselves and between African countries and countries on other continents. The majority of these collaborations take several forms, including the physical mobility of academic staff and students, networking in terms of research and libraries, and collaboration in the areas of curricula development, programmes, seminars and conferences, and publications (Zeleza 2005: 1). Attention to internationalisation in Africa is being formalised through continentwide, national and institutional policy agendas, in focused research overviews and analyses, and through dedicated advocacy mechanisms (Singh 2004: 272). This is captured in the efforts currently being made by the African Union (AU), Association of African Universities (AAU), Council for the Development of Social Science Research in Africa (CODESSRIA), Organisation for Social Science Research in Eastern and Southern Africa (OSSEA), and African Network for the Internationalisation of Education (ANIE), among others. African Association of Universities (AAU) considers internationalisation as an important process in the revitalisation of higher education in Africa. The association supports internationalisation that is domesticated to suit Africa's higher education and research needs (AAU 2006: 14). It is hoped that this initiative will make academic exchanges to be truly reciprocal and mutually beneficial, unlike what it has been over the years.

The University of Nairobi is a premier institution of higher learning in Africa with over 73,000 students and slightly over 1500 academic staff. It is currently among the top ten universities out of 1,307 universities in the continent based on the International webometrics ranking. The College of Humanities and Social Sciences (CHSS) that houses Korean Studies is the largest college with close to 40,000 students and 12 faculties, institutes and schools. The University of Nairobi is not spared the challenges faced by many public universities in Africa. Majority of public universities in the continent are experiencing rapid growth in student popu- 
AFRICAN

EAST-ASIAN

AFFAIRS

lation, inadequate staff numbers, increased cost of delivering quality programmes coupled with ever declining financial support from the exchequer. This is mainly because of the rapid growth in population, slow economic growth and high recurrent expenditure by national governments. These challenges have compelled public universities to expand and diversify their sources of funds while at the same time enhancing cost reduction measures, optimising use of resources, increasing productivity, and internationalising curriculum for relevance. Through internationalisation, the University of Nairobi has established a wide range of area studies with Korean Studies as one of them. The university has embraced internationalisation to improve student preparedness, internationalise the curriculum, and create a rich diversity of intercultural students and staff.

\section{Launching Korean Studies at the University of Nairobi}

The Establishment of Korean Studies at the University of Nairobi project is a three year project (1 July 2012 to 30 June 2015. It is largely funded by AKS and the University of Nairobi). The overriding goal of this project is to establish Korean studies at the University of Nairobi by launching, teaching, researching and popularising Korean studies as a multi-disciplinary programme in Kenya. The project is anchored on the already existing Memorandum of Understanding between the University of Nairobi (UoN) and (AKS). It is also supported by the other MoUs signed between the University of Nairobi and Korea University, Hankuk University of Foreign Studies, Korea Foundation and Sookmyung University. The long term objective of the Korean Studies in Africa is to produce local researchers who specialise in Korean language, culture, literature, history, politics and economics on the African soil.

The project is divided in to three calendar years which correspond to different phases in the implementation plan: curriculum development; registration of students and delivery of Korean Studies curriculum; and consolidation of the gains and reflections through an international conference. Year 1 of the project was dedicated to the setting up of the infrastructure for the Korean Studies at the University of Nairobi. The key activities were the acquisition, furnishing and the official opening of the Korean Studies office; the development of the Certificate and BA syllabi in Korean 
Studies; and publicising the project locally and abroad through essay competition, workshops and exchange visits.

With globalisation, it is becoming increasingly important to be able to speak a language other than your own in order to communicate with others. In Kenya, apart from Chinese and Japanese, Korea is increasingly becoming a significant development partner in various sectors such as economic development, the transport industry, construction, tourism, manufacturing and IT, among others. With the increasing global importance of Asia, including Korea, and the economic and cultural significance of the Kenya-Korea relationship, it is important that more Kenyans become proficient in the Korean language and Korean worldview in order to have a better communication with and understanding of the Korean people. By studying Korean, students in different fields are able to build strong foundations for their future career. They are also able to promote international exchange at the local level through fostering ties with the Korean counterparts.

\section{Korean Studies Curricula}

The University of Nairobi has developed and mounted two Koreas Studies programmes namely; the certificate course in Korean Language, Literature and Culture; and $\mathrm{Ba}$ in Korean Studies. The certificate course strives to equip learners with skills and ability to write using the Korean writing systems; explain the various aspects of Korean culture and society; and most important, express themselves in the Korean language and use culturally appropriate expressions, gestures, and actions for various cultural situations. The Bachelor of Arts in Korean Studies programme, on the other hand, aims at providing learners with the knowledge and skills that can enable them to demonstrate, through speech, writing and body language, in Korean, a mastery of the intercultural knowledge and communication skills necessary to operate successfully in social and professional environments; the bachelors programme also aims to equip learners with the knowledge necessary to: explain the literature, social development as well as current issues of Korea; carry out professional activities such as translation, text editing and technical writing; and enable them demonstrate through research, an understanding of the 
AFRICAN

EAST-ASIAN

AFFAIRS

techniques of research and presentation of research results.

One of the popular Korean literature courses taught at the University of Nairobi is Modern Korean Literature. Others are: Listening and Speaking Skills in Korean; Phonetics and Korean Phonology; Korean for Business and Tourism; Chinese Characters in Korean Writing; The Political Economy of Korean Development; and the Korean Entertainment Industry: The Wave (Hallyu). The Modern Korean Literature course unit, for example, offers a panoramic exploration of the modern Korean literature from the period of enlightenment to contemporary literature. The unit is segmented into three sections which correspond to the three significant epochs in the political history of Korea. These are the Choson dynasty, Korea under Japanese imperialism and post-independence Korea.

Some of the topics addressed are crumbling feudal society of the Choson Dynasty; importation of new ideas from the West; rising Japanese imperial power in East Asia; influence of the western style of education on literary works: the Enlightenment (Kaehwa Kyemong); emergence of newspapers; serialised novels in newspapers; classical Korean literature (shijo and kasa); new poetic style - free verse, politicising poetry; emergence of biographies; the new novel (shinsosol) written in Hangul; time reversal as a literary technique in the shinsosol; Second Period: Japanese colonial period (1910-1945); emergence of literary magazines, novels and short stories with themes of suffering, self-discovery, realistic tendencies; literature of resistance, gender and colonialism, cultural nationalism, patriotism (monjok); Third phase (1952 to contemporary): period of national division on industrialization, urbanization, alienation, governance, democracy and westernization; literature for political expression, multiculturalism; Korean Diaspora; critical analysis of literary works of the period. Listening and Speaking Skills in the Korean course unit exposes learners to Spoken Korean: pronunciation drills: individual sounds, single words, phrases and sentences; intonation in Korean; mastering the tones of the Korean language: contrastive words; oral drills for articulating new words and phrases; reading aloud short passages on simple matters, on common topics from authentic materials and pedagogically-prepared materials; aural comprehension: dictation, word recog- 
nition in minimal pairs; daily conversational skills; introduction of cultural notes and social linguistic knowledge of appropriate behaviour in a Korean-speaking society; listening to aural speech, video tapes, different types of expressions; further exercises in listening and speaking for natural flow of speech; exercises with native speakers of Korean. The Korean Entertainment Industry: The Wave (Hallyu) addresses the history and musical traditions of Korea: arirang, folk music and dance, mask plays and puppet shows; the traditional Korean Opera Pansori to the Korean wave (Hallyu); contemporary Korean popular culture; Western influences from classical Western opera, musicals and pop to K-pop music and Krock; Japanese influences of J-rock; music industry; record labels and talent agencies - training, promotion and exposure through TV variety/ reality shows, comedy shows, talk shows, endorsements by idols, music charts; the Korean Wave : spread and globalisation of K-pop music and dance through live concerts; music festivals, awards, the Hallyu stars, idols and phantoms; music censorship in Korea; practical viewing and analysis of popular K-pop music videos and recorded live shows; Korean wave in the cinema: history of the Korean film, influences from the West and Japan; genres: Korean drama for the small screen - TV serials (soap operas) and historical drama (sageuk); animation studios; recurring themes and characters in the Korean film, common clichés in Korean drama; pop idols in film; award shows; the Korean Wave in film exports; practical viewing and analysis of Korean films. The brief exploration of the content offered in selected course units in Korean Studies shows the depth and scope of the programme. The idea is to benchmark the delivery with that of the best institutions in Korean Studies in Asia, Europe and America.

In Year 2, the project focused on delivering Korean Studies to students at the University of Nairobi. The project enrolled the first group of Korean Studies students (45 in number) for BA and Certificate Courses. We were also able to receive two visiting professors with the support from Korea Foundation (KF). In addition, the project was able to acquire necessary literature for teaching; conduct a students' essay competition; start the development of the curriculum for a MA in Korean Studies; facilitate exchange of students and staff; officially launch Korean Studies 
AFRICAN

EAST-ASIAN

AFFAIRS

at the University of Nairobi and have the Coordinator of Korean Studies appointed by the University of Nairobi. In the Year 3, which is the final year of the project, we plan to consolidate the gains of the first two years of the project. The main activities include increased enrolment of students in Korean Studies programme, and hosting the international conference on Korean Studies in Africa entitled, "Korean Studies in Africa: Opportunities, Challenges and Strategies." Additional activities in the final year include exchange of professors and students, publishing the best essays from the two students' competitions, and completion of the MA in Korean Studies Curriculum.

\section{The trend of the Korean Studies in Kenya and Africa}

The implementation plan for the Korean Studies project indicates that introducing Korean Studies in African universities is a gradual process and can at times look frustratingly slow for those who may want quick outcomes. However, it is better to build a strong foundation for a foreign studies programme taking into consideration human and financial resources available, cultural differences, expectations, and different administrative structures in host universities. Using the University of Nairobi experience, I can say that awareness creation among staff, students and university administration is critical in mounting a foreign studies programme. The main question asked by students is, "what do I stand to gain by taking Korean Studies as opposed to, for example, Chinese studies?"

At the University of Nairobi, there is a lot of enthusiasm among students reading Asian Studies. They can either register for BA in Korean Studies or for a Certificate Course in Korean Language, Literature and Culture. Compared to Chinese Studies offered by the Confucius Institute, the main drawback is lack of financial support. All students must pay fees for all the course units they register for. This has affected enrolment in Certificate course and to an extent the BA programme. We have tried to address this by providing partial scholarships to students. We hope to find ways of providing incentives to pioneers in Korean studies to retain the numbers and hopefully attract many students. The next level is in starting a postgraduate programme in Korean studies. We are developing a MA in Korean Linguistics curricu- 
lum. In Kenya, having a multidisciplinary postgraduate is unpopular. As such it has not been possible to mount an MA in Korean studies. We have therefore opted for a discipline-based MA in Korean Studies syllabi. We hope to have the syllabus in Korean Linguistics approved by the University Senate in March 2015. This will allow the university to admit MA students in September 2016 to further their education in Korean studies locally. By that time, the first crop of Korean Studies students currently enrolled in the BA programme will have completed their course. We believe that the future of Korean Studies in Kenya and Africa lies in the ownership by students. This explains why we are investing a lot in strengthening the Koreas Studies Association in Kenya (KOSAK). This association has taken leadership in creating awareness on Korean studies, mobilising students to register for the courses and conducting community service to popularise the idea of Korean studies. Through the AKS project, we have been able to support the association to implement its activities.

\section{The Studies Project results in Kenya and Africa}

The main result of the project is the realisation of the broad objective of delivering Korean Studies course units in a Kenyan University. The Korean studies office has become a rendezvous for both Kenya government officials keen to know more about Korea and its education system, and Korean private and official visitors to Kenya. In February 2014 we officially inaugurated the Korean studies at the University of Nairobi. The chief guest was the outgoing Korean Ambassador to Kenya, HE Kim Chan-Woo. It was his personal dream to leave when Korean studies had been launched at the University of Nairobi. He realised this dream, just before his departure. When we registered the first students in September 2013, we only had 10 students. This number increased to 45 students shortly. Some of the results of the project are:

- Increased employment and internship opportunities with Korean companies for students with Korean culture and language background in Kenya.

- Increased awareness of Korean studies through university wide "Students' Essay Competition" and award of prizes to winners in three consecutive 
AFRICAN

AFFAIRS

years.

- $\quad$ There is increased participation of Heads of Departments through the Korean Studies Committee.

- $\quad$ Enhanced exchange of staff and students. This year, a professor from the University of Nairobi has reported to Hankuk University of Foreign Studies in early September to teach Kiswahili for two years.

- $\quad$ Korean Studies Curricular for Certificate, BA courses developed for use at the University of Nairobi

- $\quad$ An International Conference on Korean Studies in Africa to be held 12-13 December 2014.

The Korean Studies project has created awareness of Korean studies in Kenya. We receive enquiries from Kenyans keen to study the Korean language, culture, literature and history for various reasons. Nairobi serves as a hub for East Africa in terms of people-to-people exchange, business transaction and cultural promotion. Thus, if the Korean studies are established at the University of Nairobi, which is a prestigious public university in this region, the Korean studies and culture will be expanded to the entire Africa region. Considering that there has not been any Korean studies set up in sub-Saharan Africa, this project will be a milestone for students, academicians, citizens, and business people interested in cultural and academic exchange between Korea and Africa.

The strategy we employed in popularising Korean Studies at the University of Nairobi involved learning from the experiences of the Confucius Institute and German Studies. We involved the University administration in the project by appointing the Principal of the College as the project Director. This has ensured ready administrative support whenever we have needed it. We then formed the Korean studies Project consultative committee comprising Heads of Department of Linguistics, Political Science and Public Administration, Philosophy and Religious Studies, History and Tourism and Literature. This committee has ensured broad ownership of the project. It has also made it possible for the Depart- 
ment to identify specialists in East Asian Studies to handle Korean Studies Units. To involve the students, we have always conducted activities such as essay competitions on Korean Studies, and a Korean gala. Such competitions encourage students to read, research and discuss Korean cultural, economic and political ways of life. We have also facilitated the formation of the Korean Studies Association in Kenya (KOSAK). The association is run by students under the guidance of a patron who is currently the KF visiting professor.

In our assessment, there are not many Universities in Africa offering Korean Studies. I have reliably been informed that Korean Studies is offered at a university in the Democratic Republic of Congo (DRC), University of Ghana, University of Cairo and the University of Stellenbosch. My research has however not established whether these institutions have Departments of Korean Studies or even students registered in the programme. Plans are underway to launch an Asian studies program (including Korean studies) at Stellenbosch University in 2016. It would be highly beneficial to identify Korean Studies institutions in Africa for purposes of regional networking and experience sharing.

\section{Proposals on strengthening Korean Studies in Kenya and Africa}

Korean Studies has a promising future in Africa. Nevertheless, it still has a long way to go to enhance its visibility and impact in local universities. There seems to be a lot of infrastructural support available for institutions running Korean Studies programmes in Korea. However, these initiatives as scattered between ministries or are delivered based on different policy considerations. It is important that there is a well-coordinated, multi-sectoral approach to Korean Studies programmes in Africa.

The Korea Foundation is doing an excellent work in establishing Korean Studies professors and chairs at distinguished international universities such as the University of Nairobi. This should be sustained and expanded in other institutions in Africa. The two professors sent to the University of Nairobi in August 2013 were instrumental in making the teaching of Korean language and Economics take off smoothly. Such efforts are the most important drivers in developing and growing 
AFRICAN

EAST-ASIAN

AFFAIRS

Korean Studies worldwide. There is the need for AKS to continue liaising and lobbying KF, Korea International Cooperation Agency (KOICA), Korea TradeInvestment Promotion Agency (KOTRA) and other relevant agencies to support universities offering Korean studies in Africa.

AKS should host a consultative meeting bringing together participants from universities implementing the Korean studies Programmes KF, Ministry of Foreign Affairs, KOICA, and other key agencies involved in supporting Korean Studies abroad, especially Africa. Such a forum should come up with a one-stop-shop for information on Korean Studies. It would assist in identifying support gaps and minimise chances of duplication.

The Korean Studies Promotion Service (KSPS) should create time and visit the implementing partners in their locations. While reports sent to AKS are valuable monitoring and evaluation tools for the projects, being on the ground to meet students, the host university leadership, and staff can make AKS understand local situations partners operate for a more productive collaboration. Such visitations can enable the KSPS staff to understand the structures and policies of the universities implementing Korean Studies programmes in order to provide the required strategic guidance to strengthen the programme.

One of the main challenges the Korean Studies programme faces at the University of Nairobi is that of being overshadowed by the Confucius Institute. The support from the Chinese government to the Confucius programme is enormous. The majority of the students who cannot raise fees are given scholarships locally while those who excel are guaranteed scholarships to study in China. The Chinese embassy also supports infrastructural development in the university on a large scale. The Confucius Institute therefore attracts many students based on these incentives.

\section{Conclusion}

As this paper has illustrated, there is potential for growth of Korean studies at the University of Nairobi, and by extension Africa. This can be realised when the host university, AKS and other relevant stakeholders work together to address teething problems which is a normal occurrence in new projects. The University of Nairobi will work closely with the 
Korea Foundation, KOICA and the Korean embassy in Nairobi to ensure that Korean Studies grows in strength and spreads to other universities in Africa.

\section{Bibliography}

Association of African Universities (AAU). 2009. Regional harmonization of higher education for Africa. Report. Accra, Ghana: Author.

Otieno, J.J. 2009. Internationalization of Higher Education in Africa: Developments, Emerging Trends, Issues and Policy Implications. Higher Education Policy, 2009, 22:263-281.

Langthaler, M.2009/2010. Does globalised education benefit development? Introductory considerations on development and power in the context of internationalisation in tertiary education, in: ÖFSE/VWU OeAD-GmbH/KOO (Hg.). Internationalization of Higher Education and Development. Zur Rolle von Universitäten und Hochschulen in Entwicklungsprozessen, ÖFSE-Edition 15, Wien:19-31.

Mohamedbhai, G. 2009. WCHE online forum discussion, 6 June. https:// communities. unesco.org/wws/admin/wche_forum.

Nyangena, W. 2010. South Korean Economic Growth Model and its implications for Kenya. AKS Bulletin.

Shweder, R. A. 2001. Moral Maps, "First World" Conceits and the New Evangelists, in L. E. Harrison and Huntington, S. P. (eds.). Culture Matter. New York: Basic Books.

Singh, M. 2004. Higher education in Africa, international co-operation and GATS, in The implications of WTO/GATS for higher education in Africa, ed. AAU. Accra: AAU. 107-18.

Wasamba, P. 2010. Collaboration between Kenyan and Korean Oral Literature Scholars: What the Academy of Korean Studies Needs to Know. AKS Bul- 


\begin{tabular}{|c|l}
\hline AFRICAN & Issue 3 \\
EAST-ASIAN & September 2014 \\
AFFAIRS & \\
\hline
\end{tabular}

letin.

Young, R. 2002. University internationalisation: its meanings, rationales and implications. Intercultural Education, 13(1): 81-95.

Zeleza, P.T. 2005. Transnational education and African universities. Journal of Higher Education in Africa 3(1): 1-28. 


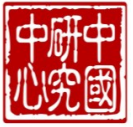

CENTRE FOR

CHINESE

STUDIES 